\title{
The Human Variome Project - Pilot project and progress
}

Richard G. H. Cotton

Genomic Disorders Research Centre

Florey Neuroscience Institutes

Melbourne, Australia

International Conference on Nutrigenomics

Guaruja, Brazil

27 September 2010

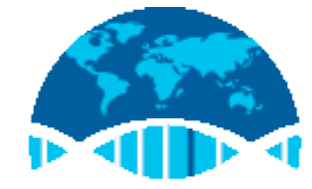




\section{What is the Human Variome Project? (www.humanvariomeproject.org)}

- Variome - Variation in a genome

- Human Variome Project - Collection \& Distribution of Human Variation \& its phenotype

- Initiated 20-23 June 2006 in Melbourne, Australia cosponsored by WHO

- A community activity to collect for databasing

- Third HVP meeting at UNESCO Headquarters, Paris, May 2010

References

Nat Genet, 2007. 39(4): p. 433-6.

Science, 2008. 322(5903): p. 861-2. 


\section{What is happening in Variation}

\section{Genomics}

- SNP, HapMap, and GWAS consortia providing variants and associations for NCBI/EBI

\section{Genetics}

- 1000 Genomes, Cancer Genomes

- Diagnostic labs/Clinicians gathering data for patient care - Locus Specific Databases (LSDB)

- Little incentive for public sharing of latter data

- Diagnostic lab/Clinicians spend hours/days/weeks searching the web

- No agreed integrated procedure 


\section{Why is complete data needed?}

- Genetic clinicians and diagnostic lab heads consult mutation databases daily (and for hours per patient)

- Data needed to refine pathogenicity predictions

- Cohorts needed for mutation specific therapeutics trials

- Individuals with fully sequenced DNA need lists of mutations to inform themselves of risk

- Pre-marital counselling can be extended genome wide from Thalassemia when we all have our genomes sequenced 


\section{Ultimate need}

- A public catalogue of curated variation in each of 20,000 genes \& associated phenotypes/studies

- An automated system of submission and review

- Improved genetic healthcare and research outcomes

- Costs and tasks will be shared worldwide 


\section{What is needed for inherited} diseases?

- Worldwide agreed standardised systems, methods and standards to make submission/collection and sharing an easy and rewarding process

- A system which allows rapid access to all mutations by clinicians and laboratories to provide the best possible genetic healthcare (diagnosis, prognosis and therapy) and research

- A system for Locus Specific Databases (LSDBs) (genespecific databases) for each gene/disease which are up to date and properly curated to eliminate errors. 


\section{What is the HVP trying to do?}

Aims to:

- Improve health by unification of data

- Support collection and use data

- Gather experts and expertise to inform the task

- Worldwide inclusive project

- Planning Meeting held May 2008

- Roadmap approved April 2010

- Implementation Meeting - Paris, May 10-14, 2010 with the support of UNESCO

- Incorporation HVP International Sept 2010 


\section{Who will use the data?}

- Clinicians

- Diagnostic lab heads

- Companies for cheap diagnostic strategies

- Researchers in therapy

- Personalised medicine companies

- Those with personal genomes 
Factors mitigating against mutation capture

- No time available for submission

- Mutations and clinical detail documented by different individuals

- Ethical considerations

- New paradigm needed

- New software needed

- Accepted portal needed to relevant database

- Accepted database needed 
A proposed pathway

I Patient phenotype

\section{HOSPITAL}

III Pathology $\longrightarrow$

$\mathbf{V}$ Clinic file $\longleftarrow$ IV Patient profile

II Patient genotype 


\section{HVP Working Groups}

- Ethics

- Education

- Data Collection from Clinics

- Data Collection from Laboratories

- Data Transfer, Databasing \& Curation (Gene Specific/LSDB)

- Overall Data Integration and Access

- Assessment of Pathogenicity

- Publication, Credit \& Incentives

- Country Specific Collection

- Funding Mechanisms and Sustainability

- Nomenclature and Standards

- Translation to Healthcare 
Projects which have progressed well

1. Nomenclature

2. Database content

3. Software

4. Central DB connectivity

5. Ethics

6. Disease pilots InSiGHT/Colon Cancer

7. Country pilots 


\section{HVP Working Group - Ethics}

Co-Chairs: Sue Povey (UK)

\section{Carol Barash (US),}

Aim: Practical protocols (SOP) for LSDB curators

- Past ethics guidelines by lawyers and other noncurator persons

- Recently by Cotton et al Hum Mutat 26(5):489 (2005) for LSDBs

- Currently S. Povey clinician and curator (TSC1+2) to generate protocol by and for curators (in press) 


\section{HVP Working Group - Education}

Co-chairs: Linda Roberts (US),

\section{Elizabeth Shephard (UK)}

- Education survey initiated to see where Working Group is headed

- HVP Session ASHG meeting Nov 1, 2010 


\section{Working Group -}

Data Collection from Clinics

Co-chairs: Peter Byers (US),

$$
\text { David Rimoin (US) }
$$

Discussion Leaders: Garry Cutting (US),

Gabriela Möslein (Germany)

- Software in development

- Form publication:- Hum Mutat, 2007. 28(10): p. 931-2. 


\section{HVP Working Group - Data Collection from Laboratories}

Chair: Graham Taylor (UK)

Discussion Leader: Sue Richards (US)

- Form publication:- Hum Mutat, 2007. 28(10): p. 931-2.

- Software in development

- DMuDB system (UK) 
HVP Working Group -

Data Transfer, Databasing \& Curation

(Gene Specific/LSDB)

Chair: Johan den Dunnen (Netherlands)

Discussion Leader: Arleen Auerbach (US)

- LOVD

- Developed by J. den Dunnen/HGVS (www.lovd.nl)

- Open access and free to download

- UMD

- Developed by C. Beroud (www.umd.necker.fr/)

- LSDB to central DB agreement

- LSDB content publications

- Reference sequence 
HVP Working Group -

Overall Data Integration and Access

Discussion Leaders: Anthony Brookes (UK),

Donna Maglott (US)

- GEN2PHEN group

- NCBI initiatives

- NCBI, UCSC and EBI support letters

- UCSC Genome Browser and NCBI have mounted LSDBs 


\section{HVP Working Group - Assessment of Pathogenicity}

Discussion Leaders: Marc Greenblatt (US), Sean Tavtigian (US)

Aim: To derive general method to assign pathogenicity or not to variants - unclassified variants (UV)

- S. Tavtigian - Major IARC meeting Feb 2008

- 8 papers published in Human Mutation (2008) from meeting and are open access

- BRCA collaborators currently have meetings to decide pathogenicity

- InSiGHT has key committee

- Ideally algorithm to give category for chance of pathogenicity 
HVP Working Group -

Publication, Credit \& Incentives

Chair: Myles Axton (US)

Discussion Leader: John Burn (UK)

Aim: To encourage and reward submission

- Microattribution campaign - M. Axton (Editorial, Nat Genet Aug 2007)

- Collect mutations from around world in gene and publish in one update - Nat Genet \& Hum Mutat

- WayStation project - C. Talbot Jr. (www.centralmutations.org) 
 \\ HVP Working Group - Country Specific Collection}

Co-Chairs: Raj Ramesar (Sth Africa), Jumana Al-Aama (Saudi Arabia)

Discussion Leader: Joji Utsonomiya (Japan)

Aim: To collect all instances of mutations from all labs in a country

- Pilot 6-8 countries - Australia, Japan, UK, Korea, Spain

- Submit to LSDB/NCBI

- Establish/Procedure applicable to all genes

- Human Genetic Societies

- MutDB model (UK) - G. Taylor

- FINDbase/Ethnic databases model - G. Patrinos

- InSiGHT to model for four genes - F. Macrae

- Funding for Australian Node of the HVP 


\section{HVP Working Group -}

\section{Funding Mechanisms \& Sustainability}

Chair: Michael Katz (US)

Discussion Leaders: Richard Cotton (Australia),

$$
\text { Daniela Seminara (US) }
$$

- Heighten credentials - WHO, UNESCO

- Adopt a Gene

- Funding in countries - Spain 
HVP Working Group -

Nomenclature and Standards

- Chair: Johan T den Dunnen

- Nomenclature developed by HGVS (www.hgvs.org) over many years

- To be spread to other genetic journals

- Relevant guidelines, etc document being developed from HGVS and other sources 
Key Pilot and Affiliated Projects of HVP

- Australian Node of the HVP

- InSiGHT colon cancer database

- Nutrigenomics

- Neurogenetics Consortium 


\section{HVP Australian Node I}

Why country specific collection

- Ensuring coherent genetic healthcare for family branches in different states

- Documentation of disease found

- Development of accurate and needed care strategies

- Development of relevant and economical diagnostic strategies for the dominant ethnic group and their diaspora around the world

- Spread the load of mutation collection

- Ensure world-wide complete collection

- Increase accuracy of pathogenicity prediction 


\section{HVP Australian Node II}

- Consortium of Australian clinicians, diagnosticians and researchers

- Funding from the NeAT scheme for software and systems development to

- Collect gene variation data from diagnostic laboratories

- Linkage to clinical information

- Integration of other systems

- BioGrid

- Mawson

- CGen 
HVP Australian Node III

The Human Variome Project Australian Node will enable:

- Faster access to information

- Enhanced diagnosis

- Platform for research

- Integration with international data via gene/disease specific databases

This system will also serve as a model for collection in other countries 
The Human Variome Project Summary of Country Specific Activity 


\section{Letters of support for HVP received from individuals in following countries:}

-Argentina

- Australia

-Austria

-Belgium

- Canada

- France

- Germany

- India

-Japan

-Mexico
-The Netherlands

- South Africa

-Sweden

- Switzerland

- Tunisia

- United Arab Emirates

-UK

-USA

-Zimbabwe 


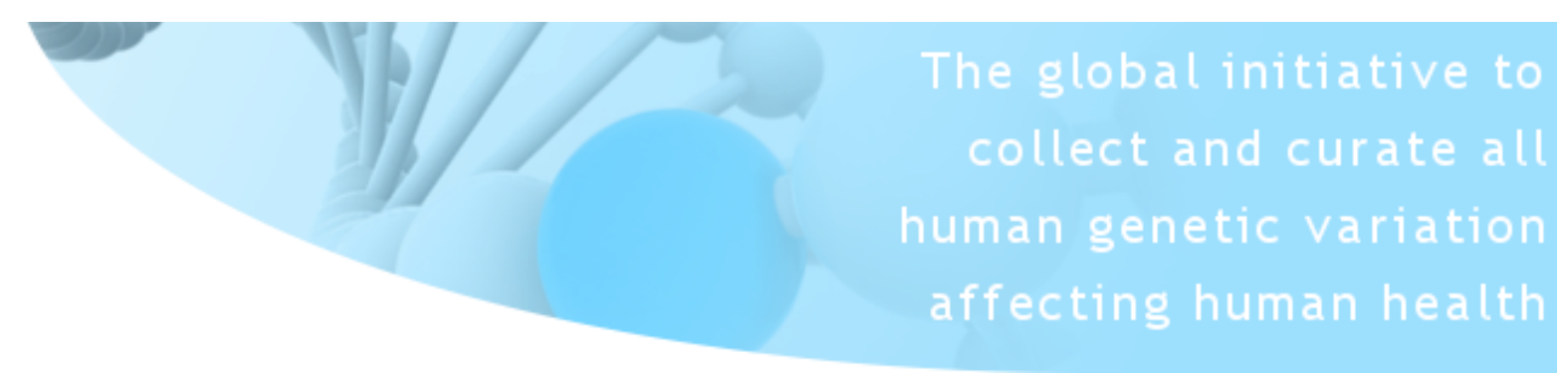

\begin{tabular}{|c|c|c|}
\hline $\begin{array}{l}\text { Have already } \\
\text { established a national } \\
\text { database (not HVP } \\
\text { Node) }\end{array}$ & $\begin{array}{l}\text { Started putting systems } \\
\text { in place for collecting } \\
\text { data for HVP Node }\end{array}$ & $\begin{array}{l}\text { Applying for/Received } \\
\text { Funding* (for HVP } \\
\text { related Project) }\end{array}$ \\
\hline $\begin{array}{l}\text { Cyprus } \\
\text { Greece } \\
\text { Israel } \\
\text { Finland } \\
\text { Singapore } \\
\text { United Kingdom }\end{array}$ & $\begin{array}{l}\text { Australia } \\
\text { China } \\
\text { Egypt } \\
\text { India } \\
\text { Korea } \\
\text { Malaysia } \\
\text { Spain }\end{array}$ & $\begin{array}{l}\text { Australia* - (June, 2009) received } \\
\text { federal finding to develop HVP } \\
\text { Australian node. } \\
\text { China - applying for funding for } \\
\text { planning and implementation of } \\
\text { HVP Chinese node } \\
\text { Korea* - (Nov 2008) received } \\
\text { government funding of } \$ 80,000 \\
\text { USD for establishing a virtual } \\
\text { Asia/Pacific Bioinformation Centre } \\
\text { (ABC) and a variome project for } \\
\text { Asia (AVP). } \\
\text { Spain* - (Oct 2009) received } \\
\text { funding from Galician government } \\
\text { to establish neurogenetics } \\
\text { database }\end{array}$ \\
\hline
\end{tabular}


Australia*

China*

Egypt $^{\star}$

Malaysia*

Russia

Spain
Argentina Israel

Australia

Belgium

China

Croatia

Egypt

Finland

Germany

Greece

Iceland

India
Japan

Korea

Kuwait

Malaysia

Russia

Saudi Arabia

Spain

Thailand

UAE 


\section{InSiGHT and}

the Human Variome Project Pilot

\section{Study Aims}

- To pilot systems to register all variants in genes predisposing to $\mathrm{Gl}$ cancer commencing with the MMR genes (hMLH1, hMSH2, hMSH6, PMS2)

- Other genes: APC, MUYTH, E Cadherin

- To be scalable to (all) other genes across the genome

- To develop country specific data nodes which

- Integrate with other systems i.e.: HVP LSDBs, and then NCBI, $\mathrm{EBI}$,

- Has ease of access

- Adaptable to all countries 


\section{Progress of the InSiGHT/HVP collaboration}

- Governance of the InSiGHT MMR gene database established, terms of reference agreed.

- Three related databases have merged and interacted through the InSiGHT database: The InSiGHT, Newfoundland, and the Dutch MMR missense database 500-10,000 \& 20,000 hits/month

- Curation of database (M Woods, A Dowty, Jan 09)

- LOVD (Leiden Open Variant Database) selected

www.insight-group.org

www.med.mun/ca/MMRvariants/

www.mmruv.info

Finlay A. Macrae 


\section{Current Plans}

- Incorporation of InSiGHT and registration as a charity (Jan 2010)

- MTA and MOU with UK DMUDB to upload all UK diagnostic lab variants

- Testing of phenotype data extraction at clinic level (Australia, Denmark, Sweden, Germany, Israel, others welcome)

- Assignment of pathogenicity derived from IARC/InSIGHT Bayesian analysis (S Tavtigian; M Greenblatt; S Lipkin)

- Mature operations of the Interpretation Committee (Paris, 2010)

- Software development for integration of disparate strands of data (Australian BioGrid, grant application to NCl (M Greenblatt, March 2009)

- National node connectivity development (NeAT grant, Australia, 2009-12)

- Communication strategies with NCBI and EBI (D Maglott, P Flicek: to do)

- Upload more national MMR data to the InSiGHT database

- Fund raising to support curation, and governance and, interpretation committees ("Adopt-a-gene"; New York fun run)

- Curator appointed Sept 2010 


\section{General Handling of Functional Variations}

-Define genotype and its effects

-Establish flows

-Establish databasing and access

-Establish curation

-Recent areas: - Inherited disease

- Pharmacogenomics

- Nutrigenomics

- Not "SNPs"/ Association Studies 


\section{Databasing/Display Example I-Cancer}

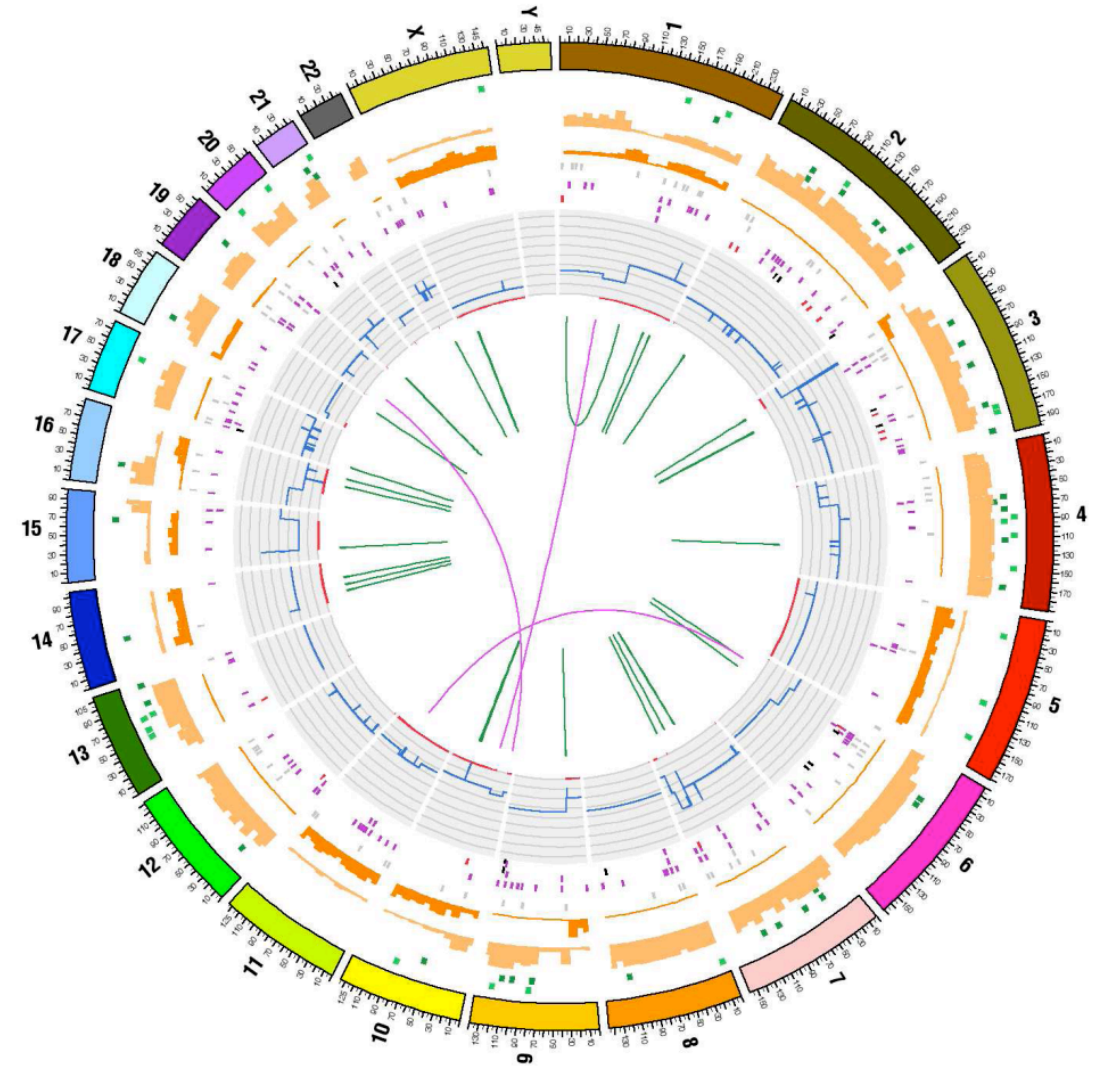

COSMIC - Display of somatic mutations in tumours www.sanger.ac.uk/genetics/CGP/cosmic/

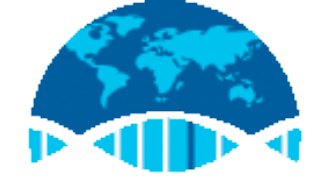

THE HUMAN VARIOME PROJECT 


\section{Databasing/Display Example II - VariVis}

zoom: $\mathbf{D} \mathbf{n}$ - I Copy Sequence

range: 250

view: Standard View I Legend
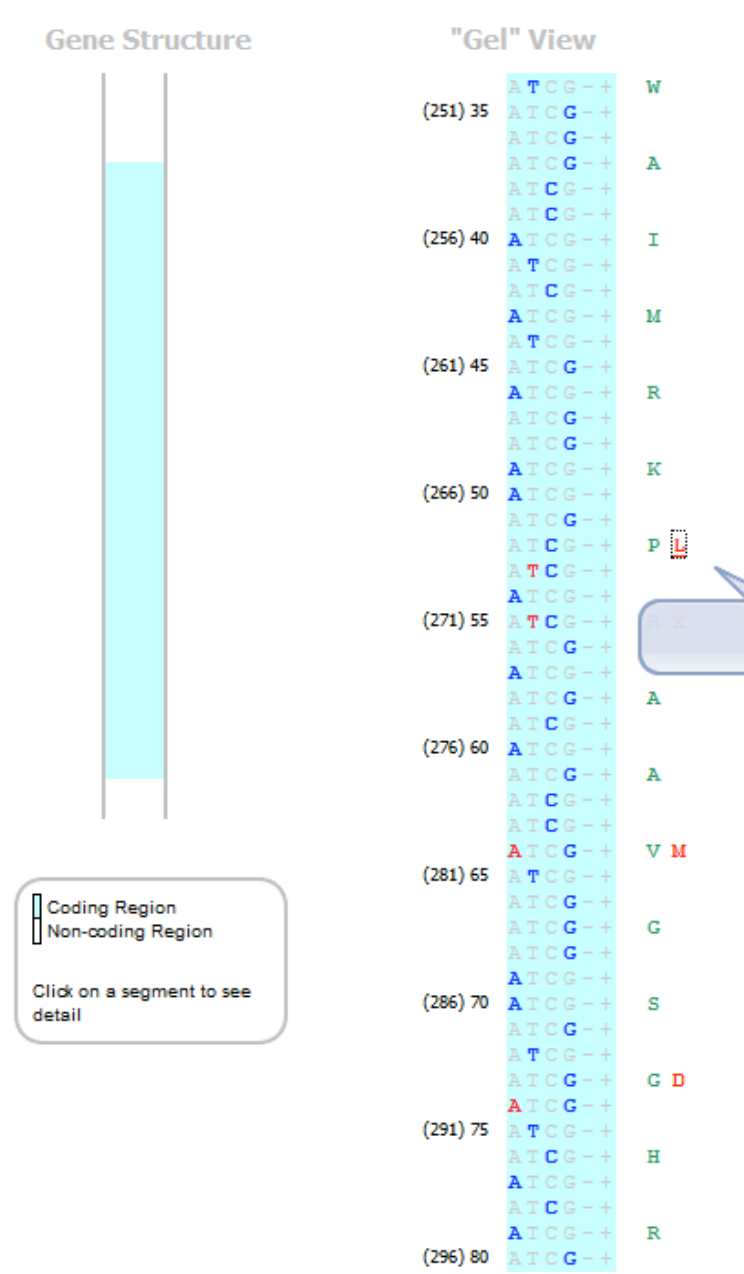

Variant Details

Variant Name: c. $53 \mathrm{C}>\mathrm{T}$

Protein: p.Pro18Leu

RE-Site: N/A

Phenotype: Unknown

Remarks: Discovered via direct sequencing

Further Information:

PublMed Google

Timothy D Smith and Richard GH Cotton,

"VariVis: a visualisation toolkit for variation databases."

BMC Bioinformatics 2008, 9:206

THE HUMAN VARIOME PROJECT 


\section{Nutrigenomics Variation}

-Variation in transport and metabolism of metals and vitamins

-Leads to variation in health outcomes

-Phenotype: - physical signs - pernicious anaemia

- in vitro transport / metabolism

- protein change

-Genotype: - base change in gene - HGVS Nomenclature

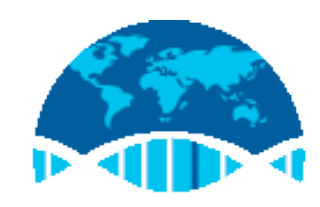


The Micronutrient Genomics Project Operational Pipeline

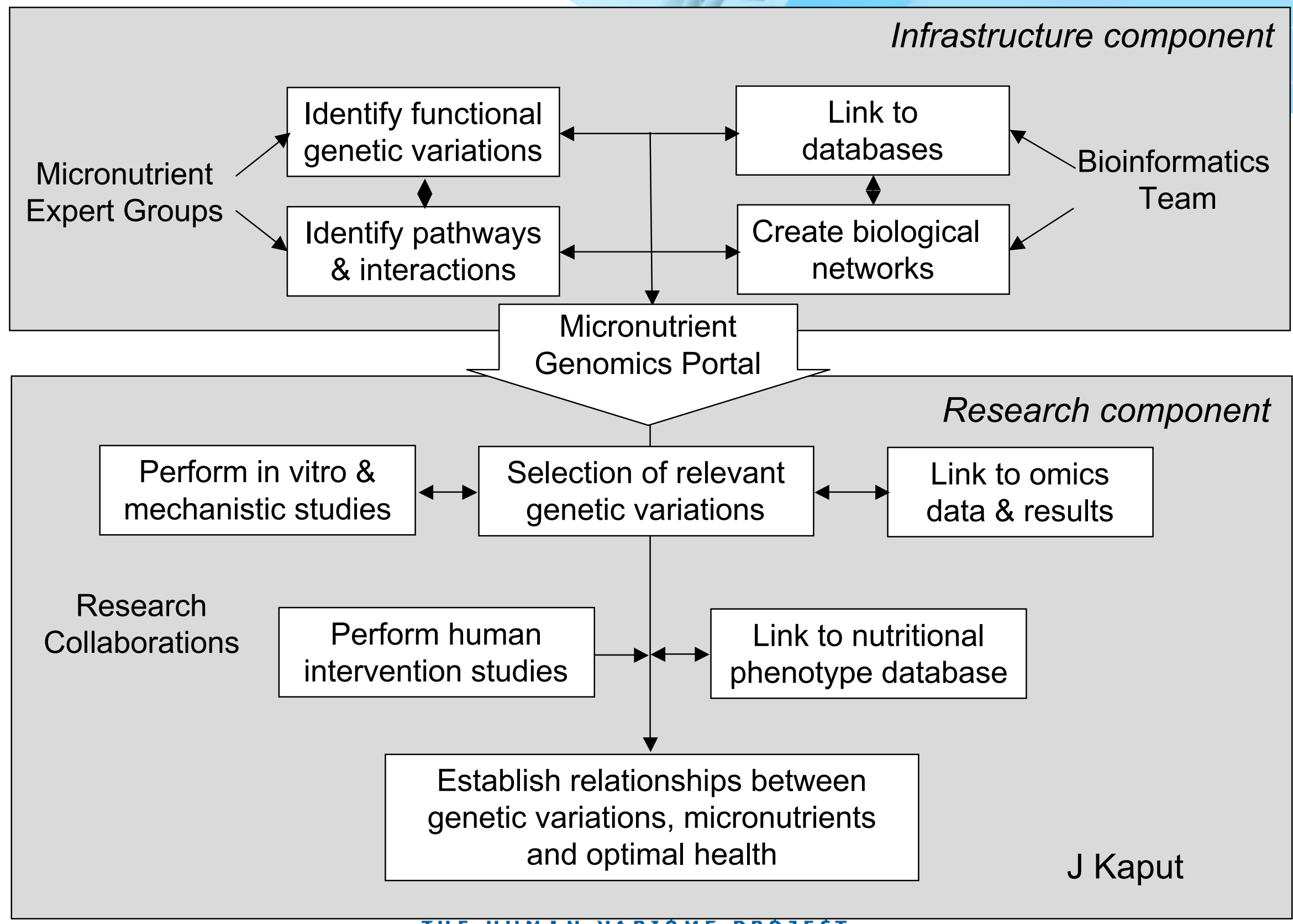

THE HUMAN VARIOME PROJECT 


\section{Recent Meetings' Publications}

1. Satellite UNESCO HVP Meeting, Paris, May 2010 Kaput et al - in press

2. Publications - in preparation

3. NuGO Website: www. nugo.org

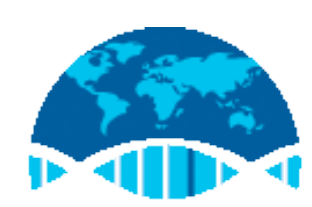




\section{HVP Neurogenetics Consortium}

- Precipitated by a HVP article in Science (2008. 322(5903): p. 861-2) featuring Neurogenetics

- Initiated at GDRC/HVP Forum in Honolulu 19 October 2009 - 80 attendees

- Funding from local Spanish Government for Dr. M-J. Sobrido

- Steering Committee of 8 leading neuro-geneticists from Spain, Germany, USA, UK, Egypt and Belgium

- Satellite meeting 10 May 2010 at HVP meeting at UNESCO

- Spastic Paraplegia database meeting Sept 2010 


\section{M-J Sobrido}

\section{Some challenges for neurogenetic LSDBs ...}

> Current database situation in neurogenetics insufficient / inefficient:

$>$ Different structure and nomenclature, difficult interoperativity

$>$ Many genes/disorders not covered: spastic paraparesis, dystonias...

$>$ Genes/disorders duplicated, information difficult to compare or misleading

$>$ Insufficient multidisciplinary knowledge in curating teams

$>$ Need standards:

$>$ Phenotype (TRAITS vs syndromes, subclinical information)

$>$ Assessment of pathogenicity

$>$ Needs combination of methods (bioinformatics, functional...)

$>$ Needs expert, disease-centered standards

$>$ Specific mutation types (mitochondrial, repeat expansions)

$>$ To capture evidence from association studies

$>$ Database structure and data submission

$>$ Ethics

$>$ Need strategies:

$>$ To ensure collection of genetic data

$>$ To ensure collection of clinical data 


\section{Some suggestions / directions towards solutions}

$>$ Develop a neuro-phenotype ontology with descriptors at the level of signs/symptoms in addition to syndromes

$>$ A good start could be integration of data in existing databases

>Quality stamp" for phenotype data: introduced once vs follow-up available

$>$ Develop databases and informatic tools that support future upgrading of information content but are not continously changing

$>$ Agree upon a consensus database tool/structure

$>$ Work together with big research groups producing high-throughput data to capture funding from key agencies

Look for a model health institution with informatic records to go back to 


\section{M-J Sobrido}

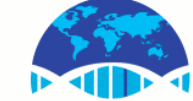

HUMAN VARIOME

PROJECT

Neurogenetics consortia and country-specific collections

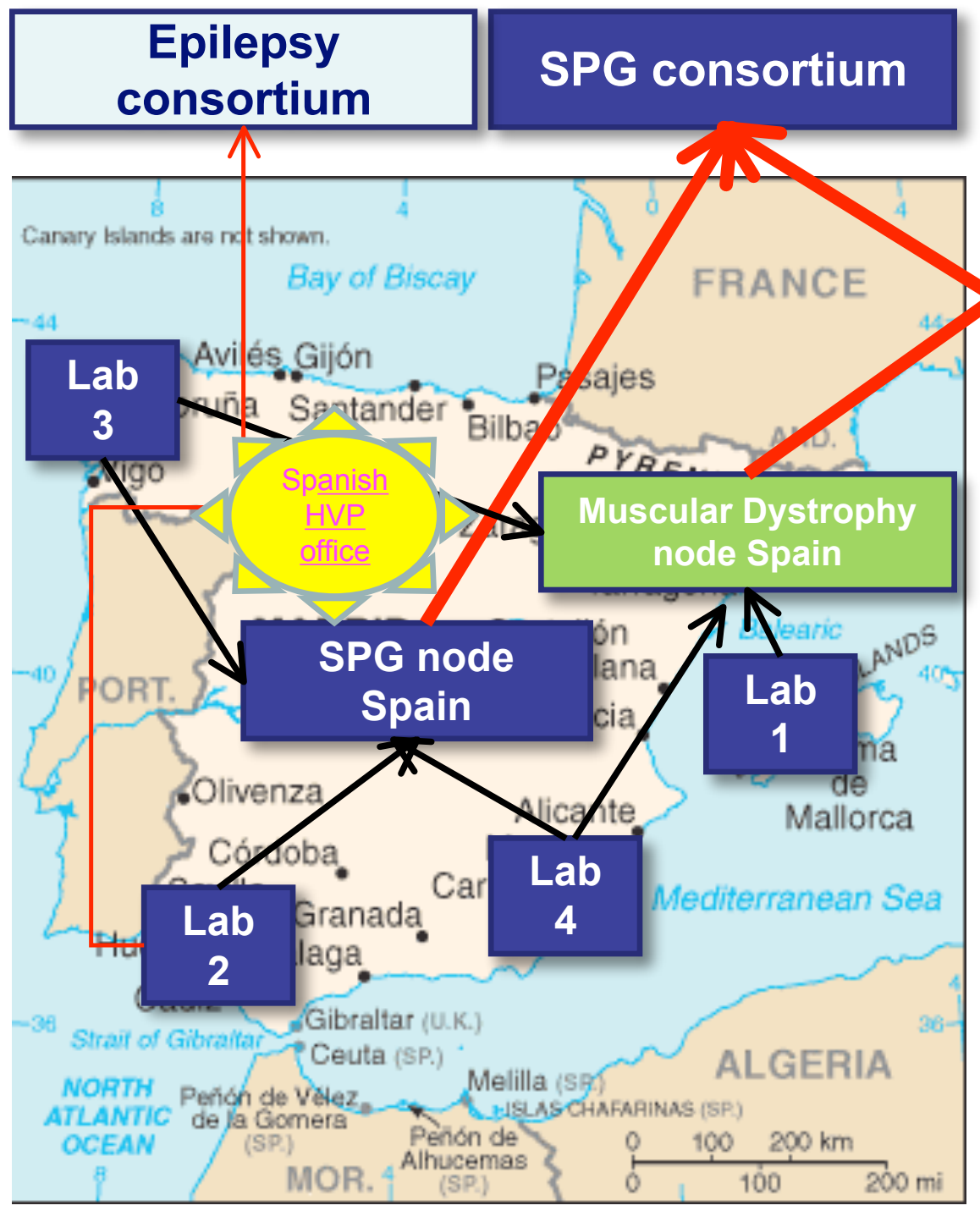

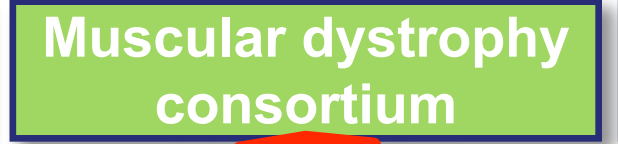

\section{Inherited neuropathy} consortium

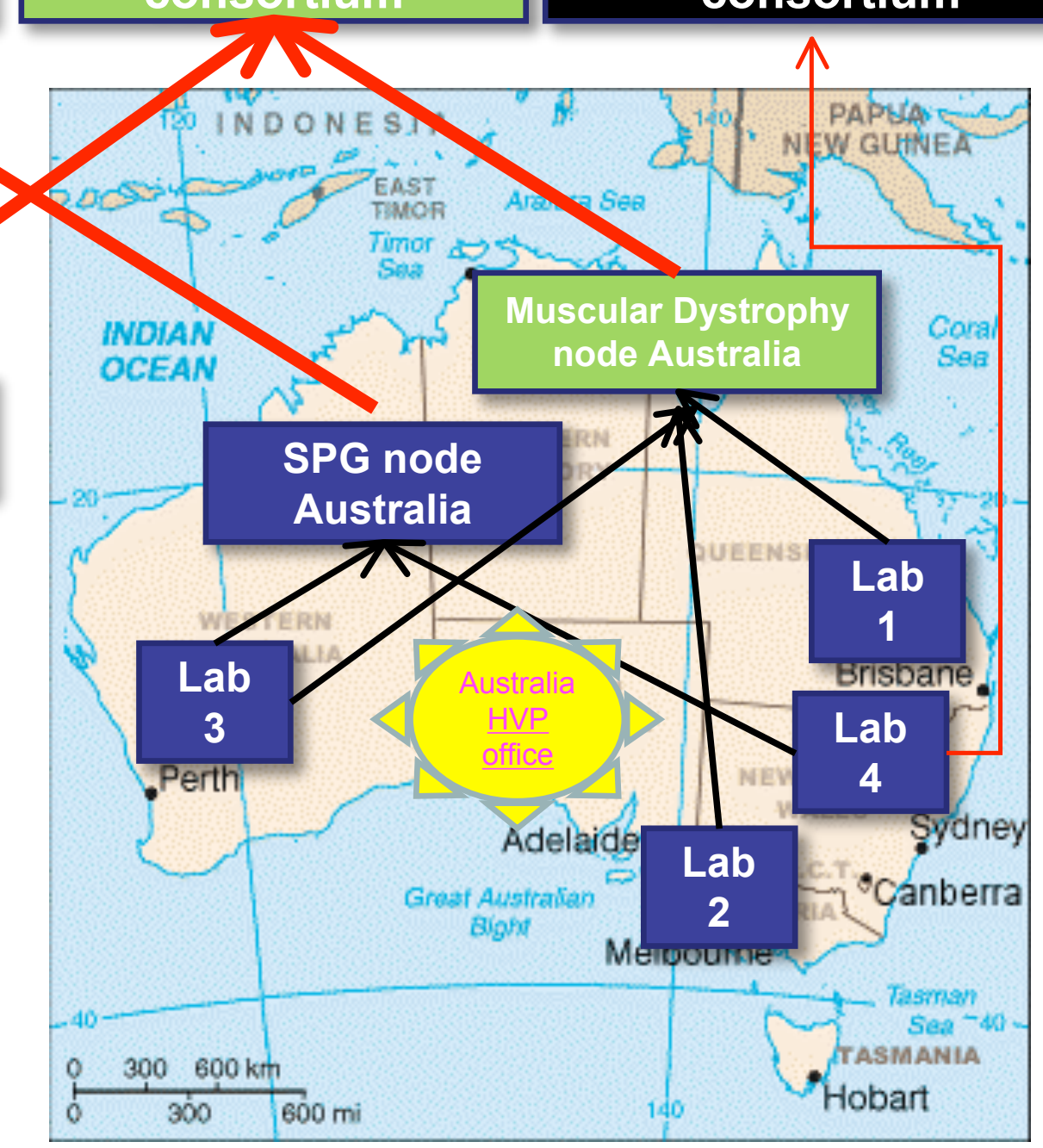




\section{Strategies to ensure collection}

- Journals demand data submission as a condition for publication

- Novel publishing strategies to ensure reward for publishing

- super reviews

- electronic publication

- microattribution

- Mutation submission a condition of grants involving mutation discovery

- Mutation submission a condition of laboratory licensing

- Mutation submission a condition of quality assessment of laboratories

- Mutation submission part of local reporting regime

- Education of relevant clinicians and scientists

- Country \& State specific collection

- Statuary requirement of submission to registers as per cancer cases

- Manuscript published:- Genet Med, 2009. 11(12): p. 843-9. 


\section{Do you have data to submit?}

- Inherited colon cancer especially

- Neurological disease especially spastic paraplegia

- Do you wish to join:

- HVP Country or disease councils

- HVP Consortium - single person

- Please contact:

R. Cotton-cotton@unimelb.edu.au via www.humanvariomeproject.org 


\section{$3^{\text {rd }}$ HVP Meeting}

Implementation and Integration Meeting, UNESCO Headquarters, Paris. 10-14 May 2010.

- Scientific Advisory Committee elected

- Roadmap approved

- Manuscript submitted

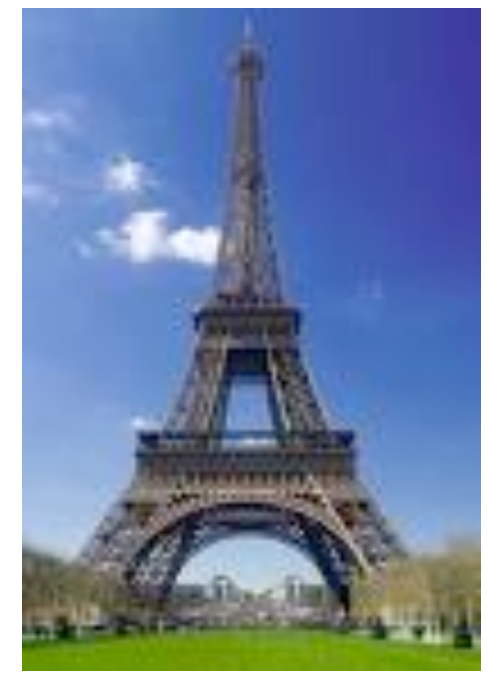

http://www.humanvariomeproject.org/meetings/paris/ 


\section{Attendees at the 1995 meeting}

R. Cotton

C. Scriver

V. McKusick

K. Fasman

J. Ostell

C. Fields

L-C Tsui

F. Hutchinson
M. Greenblatt

H. Kazazian

S. Sommer

S. Antonarakis

T. Etzold

M. Bobrow

A. Beaudet

W. Curtis 


\section{Acknowledgments to 2006}

Stylianos E. Antonarakis

Arleen D. Auerbach

Arthur Beaudet

Christophe Beroud

Ernest Beutler

Anthony Brookes

Lisa Brooks

Alastair F. Brown

Aravinda Chakravarti

Francis Collins

David Cooper

A. Jamie Cuticchia

Raymond Dalgleish

Matthew Darlison

Johan T. Den Dunnen

Mary Fujiwara

Bruce Gottlieb

Ada Hamosh

Rania Horaitis

Val Hyland

Michael Katz

Haig H. Kazazian Jr.
Heikki Lehväslaiho

Donna Maglott

Stephen Maurer

Victor A. McKusick

Shinsei Minoshima

William S. Oetting

Manyphong Phommarinh

Christopher Porter

Charles R. Scriver

Steve Sherry

Nobuyoshi Shimizu

Thomas Shows

C. Conover Talbot Jr.

Peter Tarczy-Hornoch

Graham Taylor

Lap-Chee Tsui

Edward Tuddenham

Gert-Jan van Ommen

David Valle

Mauno Vihinen

Douglas C. Wallace 


\section{Further acknowledgements $2006 \rightarrow$}

Apologies for any omissions

- Attendees at 2006 Meeting

- All LSDB curators

- David Abraham

- Myles Axton

- Agnes Bankier

- Steven E. Brenner

- Niall Byrne

- Lawrence Cavedon

- Garry Cutting

- Desirée du Sart

- David Hansen

- Terence Harrison

- Arthur Hsueh
- Val Hyland

- Shawn Jones

- Muin Khoury

- John MacMillan

- Finlay Macrae

- Christine O'Keefe

- Mark Paalman

- Sue Povey

- Tim Smith

- Nicola Stokes

- David Thorburn

- Ingrid Winship

- Justin Zobel

- Maria Jesus Sobrido

- James Kaput 


\section{Acknowledgements - InSiGHT}

- Bharati Bapat (Canada)

- Carol Burke (USA)

- John Burn (UK)

- Sue Clark (UK)

- lan Frayling (UK)

- Maurizio Genuardi (Italy)

- Richard Hamelin (France)

- Robert Hofstra (Holland)

- Maija Konen-Corish (AUS)

- Annika Lindblom (Sweden)
- Nagahide Matsubara (Japan)

- Renee Niessen (Holland)

- Paivi Peltomaki (Finland)

- Nobuyoshi Shimizu (Japan)

- Rolf Sijmons (Holland)

- Allan Spigelman (AUS)

- Joji Utsunmomiya (Japan)

- Hans Vasen (Holland)

- Mike Woods (Canada)

Finlay Macrae, Secretary InSiGHT Coordinator

Richard Cotton, Human Variome Project 


\section{Acknowledgments - HVP Planning Group}

- Richard Cotton

- Russ Altman

- Arleen Auerbach

- Walter Bodmer

- Samir Brahmachari

- Anthony Brookes

- John Burn

- Peter Byers

- Steve Chanock

- Pat Concannon

- Johan den Dunnen

- Richard Gibbs

- Li Jin
- Michael Katz

- Muin Khoury

- Mary-Claire King

- Pui-Yan Kwok

- Annika Lindblom

- Raj Ramesar

- C. (Sue) Richards

- David Rimoin

- Nobuyoshi Shimizu

- Graham Taylor

- Gert-Jan van Ommen

- Michael Watson 
Acknowledgements:

Coordinating Office

- Heather Howard

- Rania Horaitis

- Tim Smith

- Alex Kline

- Asha Herton-Crabb
- Alfreda Soetopo

- Lauren Martin

- Anne Cronin

- John Coghlan AO

- Peter Worcester 


\section{周}

HUMAN VARIOME

HVP Initiating Meeting June 2006, Melbourne, Australia

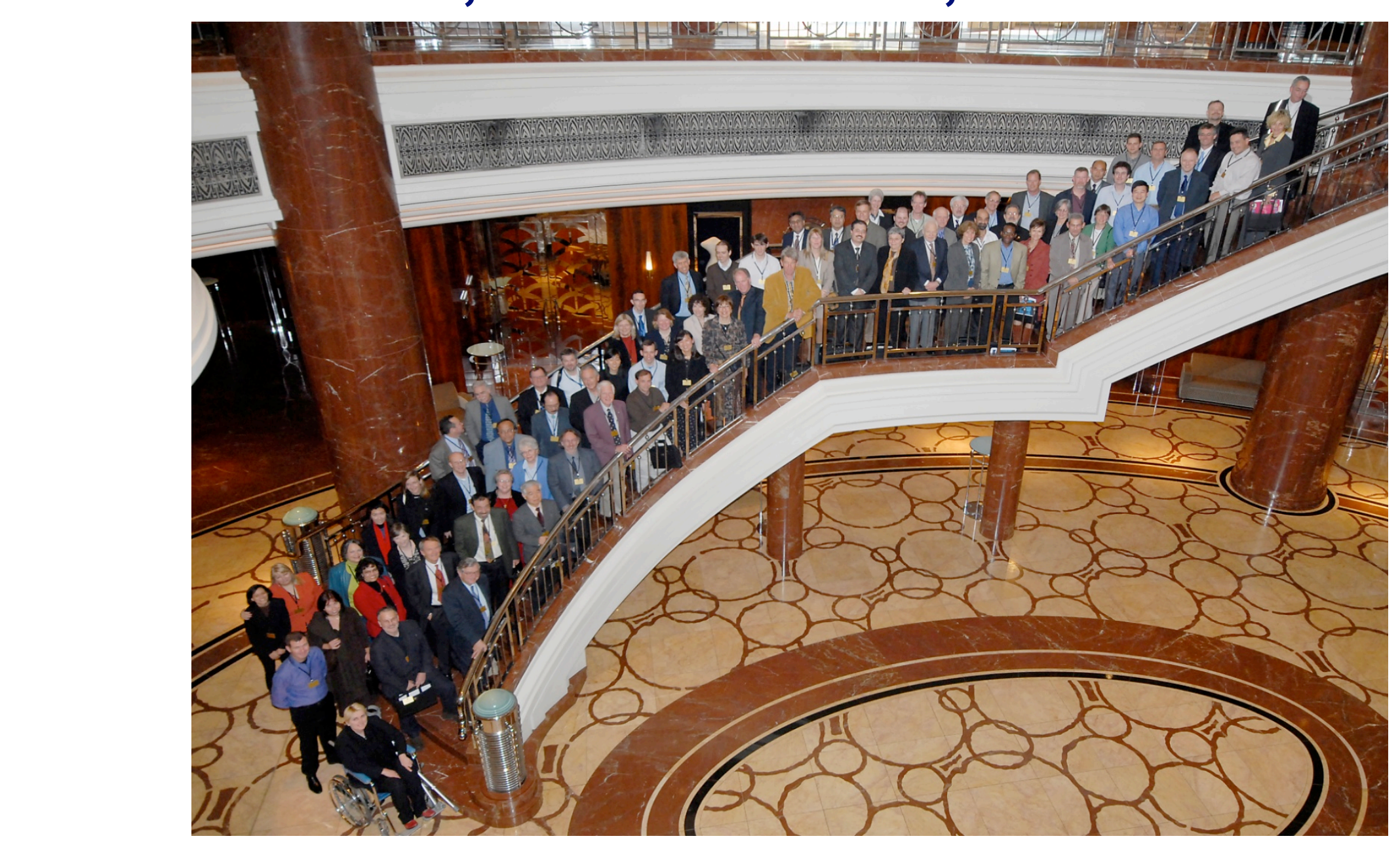

The global initiative to

collect and curate all human genetic variation affecting human health 


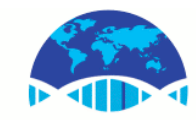

\section{HVP Planning Meeting, May 2008, San Feliu de Guixols, Spain}

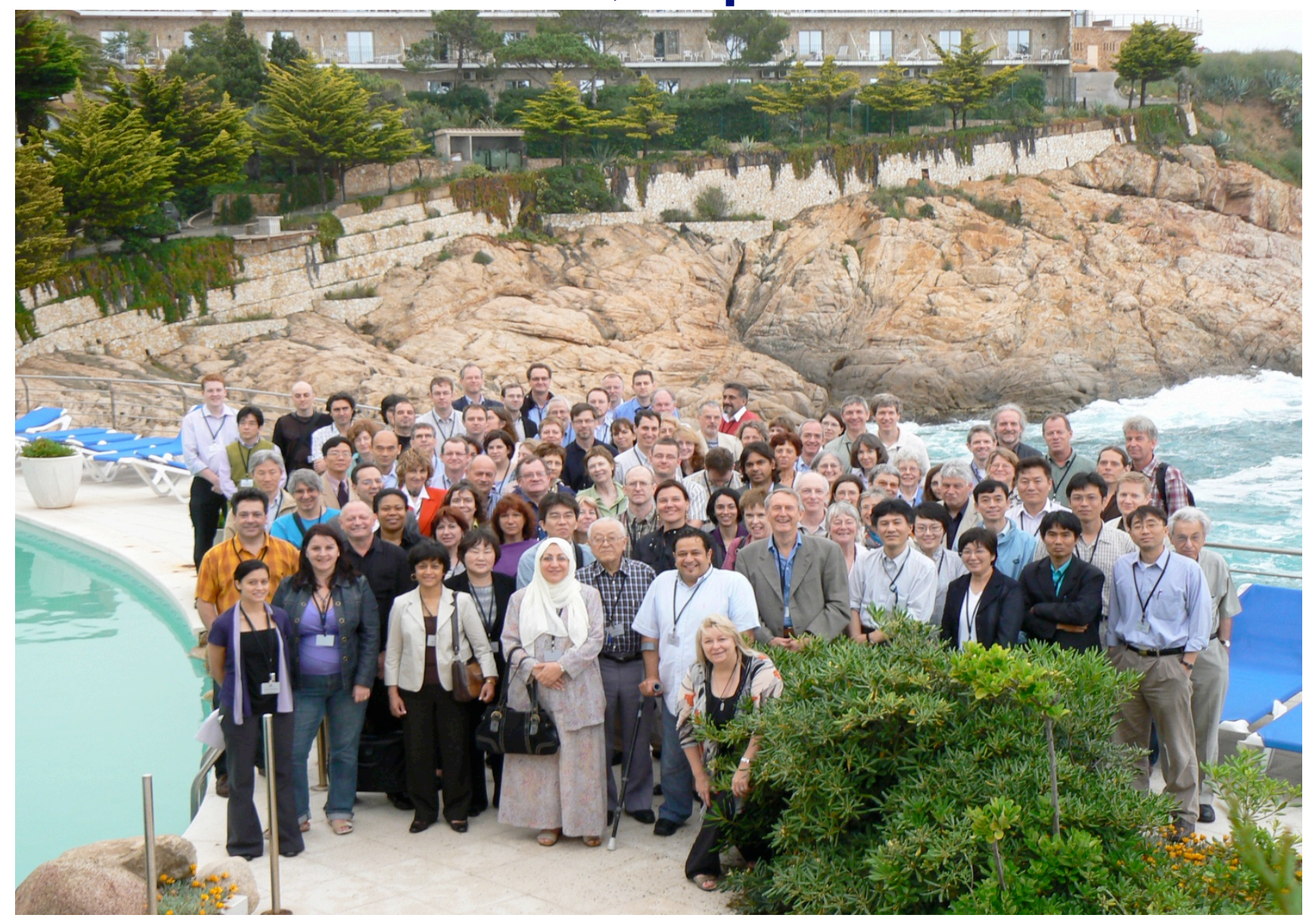


监

HUMAN VARIOME
PROJECT

HVP doesn't believe its just all work! $3^{\text {rd }}$ HVP meeting,Paris - Gala Dinner

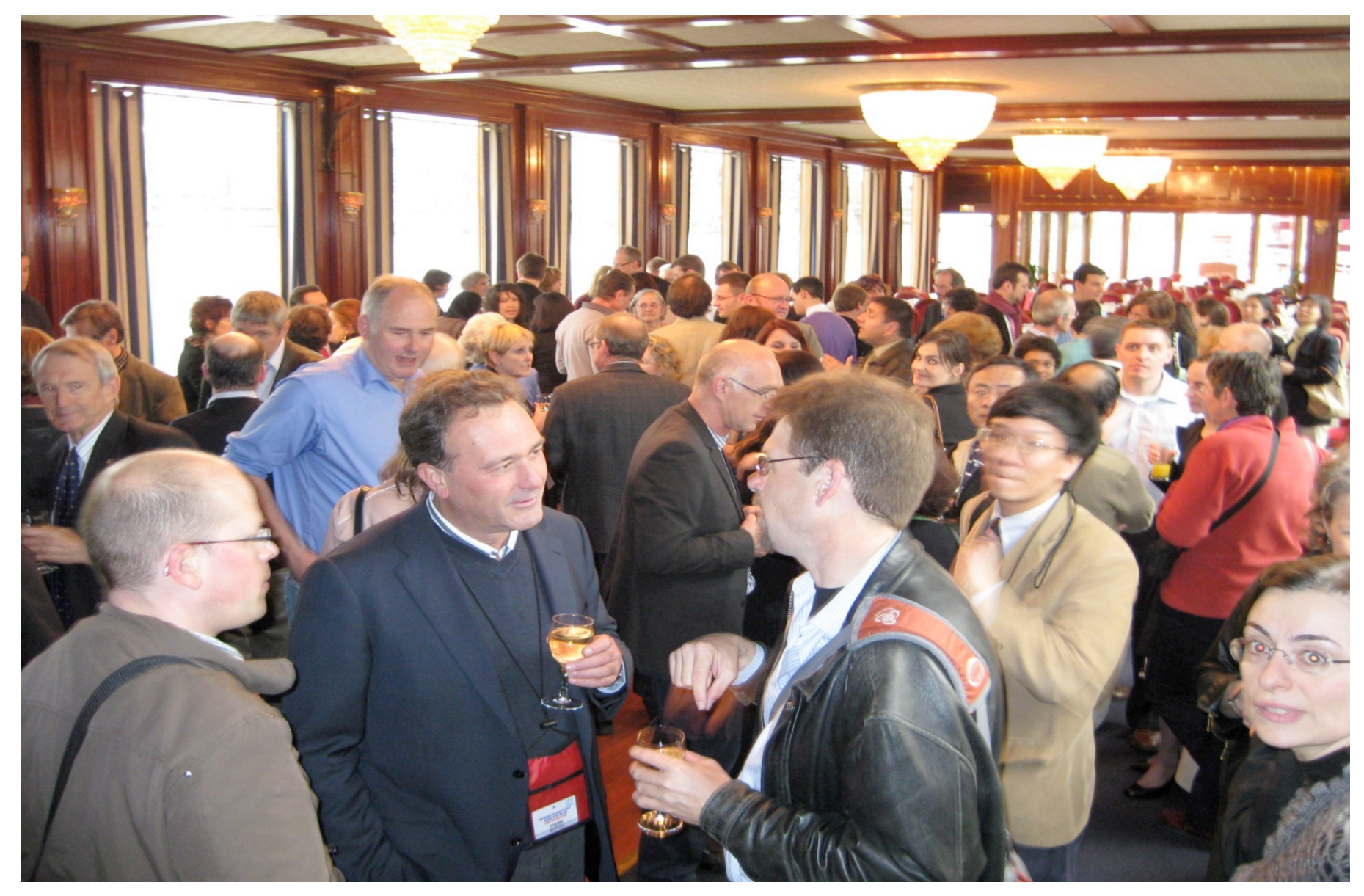




\section{Supporters}

- CASS Foundation

- Buckland Foundation

- Federal Government of Australia

- Victorian State Government

- March of Dimes

- Myer Foundation

- Gandel Foundation

- Peter and Lyndy White Foundation

- lan Potter Foundation

- University of Melbourne

- Geoff Handbury AO

- Melbourne City Council

- National Institutes of Health (US)
- UNESCO

- Lifeworks Foundation

- American College of Medical Genetics

- S\&C Mac Kinnon trust

- Australian Cancer Network

- Human Genetics Society of Australia

- JB Were Charitable Fund

- Peter Bobeff

- Quebec Network of Applied Genetics

- OECD

- World Health Organization

- Florey Neuroscience Institutes 